\title{
Mortality due to Internal Herniation As A Late Complication in A Patient who Underwent Laparoscopic Total Gastrectomy for Early Gastric Cancer
}

Ulaş ADAY, Hüseyin ÇiYILTEPE, Durmuş Ali ÇETIN, Ebubekir GÜNDEŞ, Erdal POLAT

Clinic of Gastroenterology Surgery, Kartal Koşuyolu Yüksek İhtisas Training and Research Hospital, İstanbul, Turkey

\section{ABSTRACT}

Potential spaces predisposing to internal hernias in the abdomen occurs after laparoscopic gastrectomy with Roux-en-Y reconstruction. Closure of potential spaces in primary surgery and early surgical treatment after herniation suspicion is important because of the high risk of morbidity and mortality. We hereby present the case of a patient who underwent laparoscopic total gastrectomy because of early-phase gastric cancer and who developed massive intestinal necrosis because of internal herniation in the third year of follow-up. A 60-year-old male underwent an urgent laparotomy, and ischemia in the cecum and all throughout the small intestine was observed because of small intestine herniation between the Roux limb and the meso of the transverse colon after laparoscopic gastrectomy for early gastric cancer. Following the detorsion of all the small intestinal segments, it was seen that the flow in the main branches of the superior mesenteric artery regained activity, but no significant change in coloring was achieved in the distal segments and the cecum. The patient, for whom relaparotomy was planned following stabilization, died in the fourth post-operative hour. The Roux-en-Y reconstruction performed after laparoscopic gastric resection leads to the formation of novel spaces in the abdomen. Internal herniation, which can lead to mortality, can be prevented by closing these spaces up. Moreover, it is significant to have early diagnosis and perform the necessary surgical procedure for treatment without delay.

Keywords: Internal herniation, laparoscopy, gastric cancer, Petersen's space

\section{Introduction}

Laparoscopic gastrectomy has been increasingly used in gastric cancers, especially in patients in the early phase (1). Internal herniation is a significant complication, with a rate of $6.2 \%$ of the Roux-en-Y gastric bypass procedure performed in bariatric surgery (2). It has also been reported that this rate increases in laparoscopic total gastrectomy cases performed for gastric cancers (3).

The space between the meso of the Roux limb and the meso of the transverse colon is called Petersen's space (1). Almost half of the internal herniation cases are based on the occurrence of this space. Herniation cases can be prevented by closing the Petersen's and jejuna-jejunal spaces (4-6). We hereby present the case of a patient who underwent laparoscopic total gastrectomy because of early-phase gastric cancer and who developed massive intestinal necrosis because of internal herniation in the third year of follow-up.

\section{Case Report}

A 60-year-old male patient had a stent placed in his left coronary artery through an angio performed in his right femoral artery 2 days before because of stabile angina. The patient underwent right femoral artery repair by our hospital's cardiovascular surgery team 1 day later upon the development of femoral artery aneurysm where the angio procedure had been performed. The patient was examined at a gastroenterology surgery clinic because of abdominal pain 2 days after femoral artery repair. At our examination, we found that the pain was colic type when it started the day after femoral artery repair and then it became continuous. Abdominal distension was observed $6 \mathrm{~h}$ before surgery. The patient's physical examination showed previous incision scars of laparoscopic gastrectomy. He was tachypneic, and his abdomen was distended. The patient who had no intestinal sounds had sensitivity, pain and rebound positivity. His rectal examination was normal. The

Address for Correspondenc: Ulaş ADAY; Kartal Koşuyolu Yüksek Ihtisas Eğitim ve Araştırma Hastanesi, Gastroenteroloji Received : :24.02.2016 Cerrahisi Kliniği, İstanbul, Türkiye E-mail: ulasaday@gmail.com 
patient's medical history unveiled that he underwent laparoscopic total gastrectomy because of early-phase gastric cancer 3 years before, had not received any adjuvant treatment during the post-operative follow-ups, and had been experiencing abdominal pain attacks in the form of an intermittent colic.

The patient's laboratory parameters showed high levels of acidosis and lactate in his blood gas, while his biochemistry parameters showed an increase in amylase and lactate dehydrogenase levels and a decrease in thrombocyte levels. Other routine laboratory tests were within the normal ranges. Mesenteric ischemia was considered at first because the patient had coronary vascular disease, and symptoms occurred after peripheral vascular surgery. However, his abdominal computed tomography with intravenous contrast revealed dilatation in the small intestines, a small amount of fluid in the abdomen, mesenteric torsion, and sudden cut of flow in the superior mesenteric artery (SMA) related to torsion. Further, there were air images in the hepatic inter-parenchymal portal vein branches (Figure 1). The patient underwent an urgent laparotomy (18 h after the onset of pain), and it was observed that the small intestine segments were herniated from the right to the left in the space between the Roux limb and the meso of the transverse colon. The patient had ischemia in the cecum and all throughout the small intestine and dilatation and thinning in the intestinal wall (Figure 2). There was about $200 \mathrm{cc}$ necrotic smelling and blurry fluid in his abdomen. Following the detorsion of all the small intestinal segments, it was seen that the flow in the main branches of SMA regained activity and also coloring was re-achieved in a $150-\mathrm{cm}$ segment from the proximal to the distal. However, no significant change in coloring was achieved in the distal segments and the cecum. The patient developed deep hypotension during the surgery, and there was also an increase in acidosis as seen in blood gas control. Upon these developments, the patient's abdomen was closed with a Bogota bag and was taken into the intensive care unit follow-up. The patient, for whom relaparatomy was planned following stabilization, died in the fourth post-operative hour.

\section{Discussion}

Laparoscopic surgery has advantages such as a decrease in post-operative pain, decrease in adhesion rates, better cosmetic results, earlier recovery, and lesser duration of hospitalization $(1,7)$. Many studies have demonstrated that the long-term results of laparoscopic surgery and open surgery in gastric cancers were similar $(5,8)$. Roux-en-Y reconstruction is frequently preferred because of its prevention of anastomotic leaks and reflux in laparoscopic total or subtotal gastrectomy (9). Following Roux-en-Y reconstruction, Petersen's spaces, jejuna-jejunal spaces, and transverse mesocolon spaces (if anastomosis was performed retrocolic) was formed. The herniation of intestinal structures through such spaces may lead to intestinal obstruction, ischemia, or necrosis (3-6).

Studies in the literature have reported that the internal herniation rate following laparoscopic resection for gastric cancers was between $0.2 \%$ and $14.7 \%$. The reasons for this situation

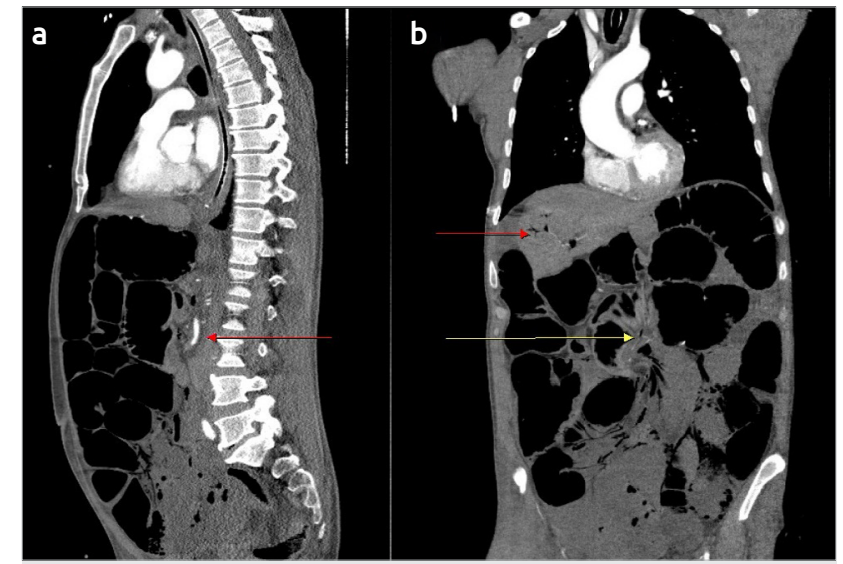

Figure 1. a, b. Tomographic image of the occlusion in the SMA (a), the torsion in the meso (yellow arrow), and the air values in the portal vein (red arrow) (b)

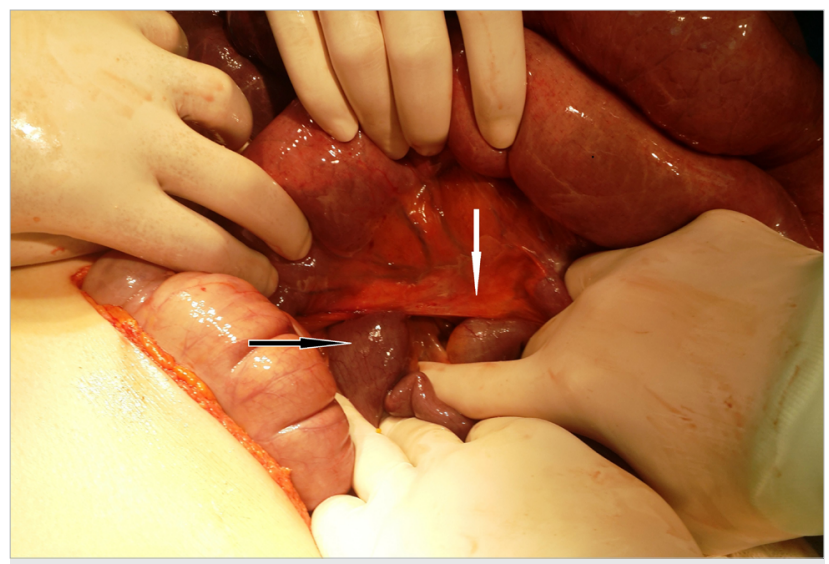

Figure 2. The intraoperative image of the meso of the Roux-limb (white arrow) and the small intestinal segments herniating beneath it (black arrow)

include the decrease in mesenteric fat tissue because of postoperative weight loss, lesser amount of adhesions following laparoscopic surgery, leaving a longer Roux limb, and the most important being not closing the formed spaces $(1,3,4$, $5,8,9)$. Internal herniation after laparoscopic gastric resection can be seen at any time after surgery, but the prevalence increases after the first year $(1,4,5)$. In a study by Kelly et al. (3), the authors stated that the rate of internal herniation following laparoscopic total gastrectomy was $22 \%$ at the end of an average of 22.4-month follow-up period. This refers to the fact that the rate of herniation in long-term follow-ups will rise in cases where formed spaces are not closed up.

Abdominal pain in the form of intermittent colic pain, sudden abdominal pain, distension, nausea, and vomiting all account for the general clinical picture in acute cases. It is significant to have early diagnosis and immediate intervention for treatment. Intestinal necrosis, which develops in the case of a delay, will lead to mortality and a significant morbidity like the short bowel syndrome $(1,3)$. Tomographic evaluation is a diagnostic tool in the majority of the cases. Mesenteric torsion and the related stopping of vascular flow, dilated intestinal loops, and 
Table 1. Studies offering the number of cases of antecolic Roux-en-Y reconstruction following laparoscopic total or subtotal gastrectomy with and without a closed up Petersen's space

\begin{tabular}{|c|c|c|c|c|c|}
\hline Author/Year & $\begin{array}{c}\text { Number of } \\
\text { patients with } \\
\text { unclosed space }\end{array}$ & $\begin{array}{c}\text { Number of } \\
\text { IH cases before } \\
\text { closing (\%) }\end{array}$ & $\begin{array}{l}\text { Number of } \\
\text { patients with } \\
\text { closed space }\end{array}$ & $\begin{array}{l}\text { Number of } \\
\text { IH cases after } \\
\text { closing (\%) }\end{array}$ & $\begin{array}{l}\text { Mean duration } \\
\text { of follow-up after } \\
\text { closing (Months) }\end{array}$ \\
\hline Kimura et al. (1)/2015 & 122 & $5(4.1)$ & 105 & $0(0)$ & 12 \\
\hline Kelly et al. (3)/2013 & 34 & $5(15)$ & 115 & $0(0)$ & 10.7 \\
\hline Kojima et al. (4)/2014 & 268 & $6(2.2)$ & 90 & $0(0)$ & 9.2 \\
\hline
\end{tabular}

acid and dilatation in the biliopancreatic segment are among the findings observed by tomography $(5,8)$. In our case, air images were also observed in the portal system in addition to these findings. Gas seen in the portal vein is a rare condition, and non-ischemic causes appear to be more common than ischemic causes during the last 20 years because the rate at which endoscopic and radiological procedures have been performed are increasing. İt is reported that intestinal ischemia with gas seen in the portal vein has a high mortality rate, about $63 \%(10)$.

It is significant to close the formed spaces because of their destructive clinical outcomes. Recent studies have shown that by closing up the space at the dorsal position of the Roux limb, herniation did not develop from this area (Table 1) $(1,3,4)$.

\section{Conclusion}

The Roux-en-Y reconstruction performed after laparoscopic gastric resection leads to the formation of novel spaces in the abdomen. Internal herniation, which can lead to mortality, can be prevented by closing these spaces. Moreover, it is significant to conduct early diagnosis and perform the necessary surgical procedure for treatment without delay.

Informed Consent: Informed consent was not obtained from patients who participated in this study.

Peer-review: Externally peer-reviewed.

Author Contributions: Concept - U.A.; Design - U.A.; Supervision U.A.; Data Collection and/or Processing - H.Ç.; Analysis and/or Interpretation - E.G.; Literature Review - D.A.Ç.; Writing - U.A.; Critical Review - E.P.
Conflict of Interest: No conflict of interest was declared by the authors.

Financial Disclosure: The authors declared that this study has received no v support.

\section{References}

1. Kimura H, Ishikawa M, Nabae T, Matsunaga T, Murakami S, Kawamoto M, et al. Internal hernia after laparoscopic gastrectomy with Roux-en-Y reconstruction for gastric cancer. Asian J of Surgery 2015; 20: 1-7. [CrossRef]

2. Al-Mansour MR, Mundy R, Canoy JM, Dulaimy K, Kuhn JN, Romanelli J. Internal hernia after laparoscopic antecolic Roux-en-Y gastric bypass. Obes Surg 2015; 25: 2106-11. [CrossRef]

3. Kelly KJ, Allen PJ, Brennan MF, Gollub MJ, Coit DG, Strong VE. Internal hernia after gastrectomy for cancer with Roux-en-Y reconstruction. Surgery 2013; 154: 305-11. [CrossRef]

4. Kojima K, Inokuchi M, Kato K, Motomaya K, Sugihara K. Petersen's hernia after laparoscopic distal gastrectomy with Roux-en-Y reconstruction for gastric cancer. Gastric Cancer 2014; 17: 146-51. [CrossRef]

5. Miyagaki H, Takiguchi S, Kurakowa Y, Hirao M, Tamura S, Nishida T, et al. Recent trend of internal hernia occurrence after gastrectomy for gastric cancer. World J Surg 2012; 36: 851-7. [CrossRef]

6. Paroz A, Calmes JM, Giusti V, Suter M. Internal hernia after laparoscopic Roux-en-Y bypass for morbid obesity: a continuous challenge in bariatric surgery. Obes Surg 2006; 16: 1482-7. [CrossRef]

7. Hirashima K, Ishikawa T, Kosugi SI, Kano Y, Ichikawa H, Hanyu T, et al. Internal hernia after laparoscopic-assited proximal gastrectomy with jejunal interposition for gastric cancer: a case report. Surgical Case Reports 2015; 1: 49. [CrossRef]

8. Yoshikawa K, Shimada M, Kurita N, Sato H, Iwata T, Higashijima J, et al. Characteristics of internal hernia after gastrectomy with Roux-en-Y reconstruction for gastric cancer. Surg Endosc 2014; 28: 1774-8. [CrossRef]

9. Hosoya Y, Lefor A, Ui T, Haruta H, Kurashina K, Saito S, et al. Internal hernia after laparoscopic gastric resection with antecolic Roux-en-Y reconstruction for gatric cancer. Surg Endosc 2011; 25: 3400-4. [CrossRef]

10. Huang CY, Sun JT, Tsai KC, Wang HP, Lien WC. Hepatic portal venous gas: Review of the literature and sonographic implications. Journal of Medical Ultrasound 2014; 22: 66-70. [CrossRef] 